\title{
Colonic obstruction and perforation related to heavy Trichuris trichiura infestation
}

\author{
J Bahon, J Poirriez, C Creusy, A N Edriss, J P Laget, E Dei Cas
}

\begin{abstract}
Laboratoire
d'Anatomie et de Cytologie

Pathologiques, Faculté

Libre de Médecine,

Université Catholique

de Lille, 56 Rue du

Port, 59046 Lille

Cedex, France

Abstract

Heavy Trichuris trichiura infestation is rare in developed countries, and complications requiring surgical intervention have been described rarely in human trichuriasis. A case of colonic obstruction and perforation related to heavy whipworm infection is described in an 84 year old woman. The woman was admitted to hospital because of a chest infection. Two days after admission she suffered nausea and vomiting followed a day later by bowel stoppage. Laparotomy indicated intestinal obstruction by a tumour. A partial right sided ileocolectomy was performed. Pathological examination of the resected bowel revealed heavy infestation with $T$ trichiura causing a pseudotumour following a proliferative inflammatory response.

(F Clin Pathol 1997;50:615-616)
\end{abstract}

J Bahon

C Creusy

Laboratoire de

Biologie, Centre

Hospitalier de

Dunkerque, France

J Poirriez

Centre Hospitalier

d'Arras, France

A N Edriss

J P Laget

INSERM-Unité 42, Villeneuve D'Ascq, France

E Dei Cas

Correspondence to: Professor Creusy.

Accepted for publication 13 May 1997

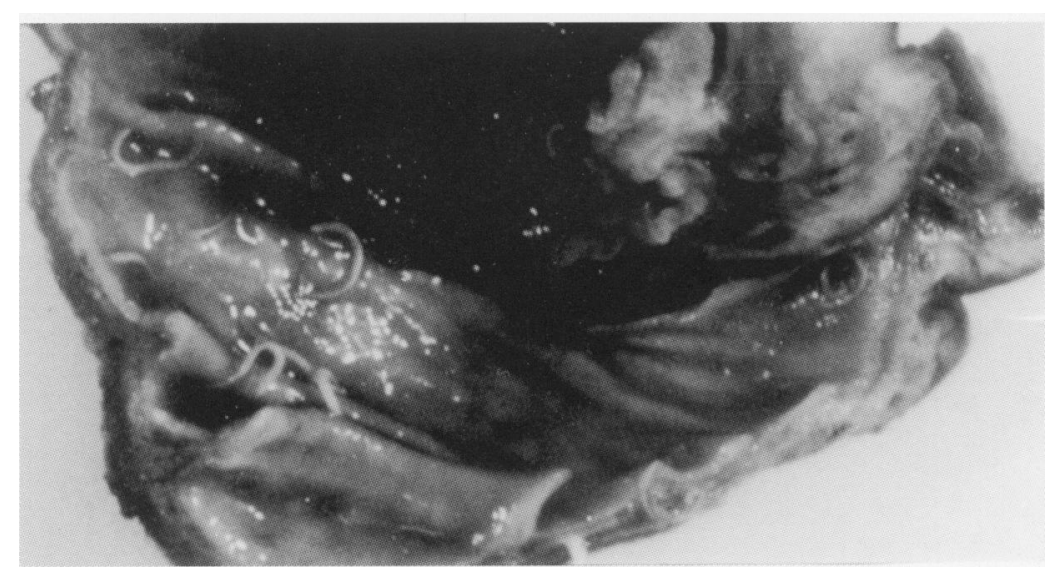

Figure 1 Numerous white thin formations on the surface of the mucosae (whipworms).

Keywords: Trichuris trichiura infestation; colonic obstruction

An 84 year old woman was admitted to a medical ward following bronchus infection. On admission, she was in poor condition, with cough, purulent expectoration, and profound dehydration. Abdominal examination revealed meteorism, without guarding and bowel stoppage. There was no abdominal pain.

Laboratory investigations revealed extrarenal azotaemia, iron deficiency, normocyte anaemia, and normal total leucocyte concentration without eosinophilia.

The patient had no relevant medical history, except diabetes controlled by diet, phlebitis, and arteritis of the lower limbs. She had suffered portal hypertension syndrome during a hospital stay one year earlier. Abdominal

echography did not show any detectable lesions

except an atrophic gall bladder.

Two days after admission the patient suffered nausea and vomiting, and bowel stoppage one day later. Abdominal $x$ ray revealed numerous air-fluid levels on the jejunum, suggesting an ileocaecal obstruction. The patient was transferred to the surgical ward and was operated on two days later. A laparotomy was performed, confirming the intestinal obstruction by a tumour, with effusion and pseudomembranous exudate. A mass resembling a neoplasm of the ascending colon, with abscess and perforation, was discovered. A partial right sided ileocolectomy was performed. No mesenteric lymph nodes were found. Postoperative recovery was uneventful.

\section{Pathology}

GROSS

Forty centimetres of the right bowel were excised with $19 \mathrm{~cm}$ of small bowel. The lesion was located in the caecum, which showed an irregular thickening of the wall. A fissural perforation was discovered with an abscess near the appendix, without evident tumour. The distal part of the appendix was normal. The mesothelium was covered with membranous exudate around the perforated area.

On the surface of the mucosae we discovered numerous white thin formations about $35 \mathrm{~mm}$ long with a thin anterior part. Some of them seemed to be partly stuck in the mucosae (fig 1). None was found in the small bowel.

\section{MICROSCOPIC}

Samples were taken from the perforated area. The external side of the perforation was covered with fibrin and purulent exudate. Deep in the wall there was an inflammatory cell infiltrate consisting on histiocytes, giant cells, plasma cells, lymphocytes, neutrophils and some eosinophils, and an extensive fibrosis in the peritoneal layer. The white thin formations discovered macroscopically were worms, some of which were partially embedded in superficial mucosal chorion (fig 2). Some amorphous debris was found inside granulomas. A few inflammatory lymph nodes were also found.

Numerous worm sections were examined. The size and the morphological features of the worms (body wall, presence of a stichosome, typical intrauterine eggs) were consistent with the genus Trichuris. Twenty mature intrauterine eggs were measured; their lengths ranged from 50-54 $\mu \mathrm{m}$ (mean $52 \mu \mathrm{m}$ ) and their widths from $22-25 \mu \mathrm{m}$ (mean $24 \mu \mathrm{m}$ ). These values are within the lower limits for eggs of the 


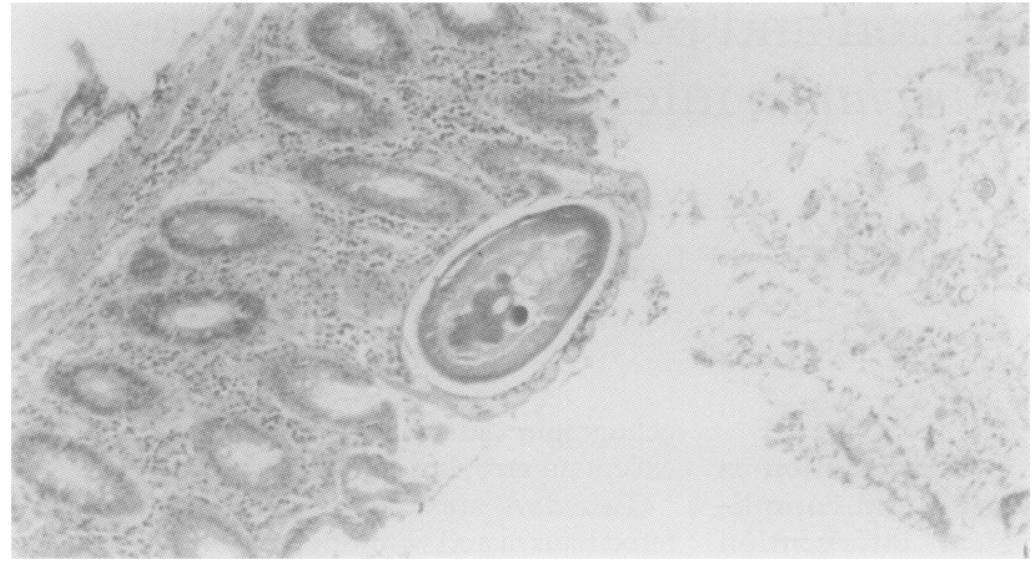

Figure 2 Transverse section of anterior portion of Trichuris trichiura embedded in superficial colonic mucosae. (Haematoxylin and eosin; original magnification $\times 400$ ).

human worm Trichuris trichiura, excluding any zoonotic infestation (from $T$ suis or $T$ vulpis ).

\section{Epidemiological data}

A short retrospective epidemiological study was done to explain this unusual heavy $T$ trichiura infestation. The patient was living in very bad conditions. She did not like cooking or washing, and she regularly ate a lot of raw vegetables, which she bought mainly from the local market. Her daughter and her son-in-law sometimes gave her vegetables from their garden, and stool examinations for them were negative; therefore, the origin of the infestation could not be determined.

\section{Discussion}

Trichuriasis is now sporadic in France; ova of $T$ trichiura are found in about $1 \%$ of the stool specimens examined because of diarrhoea in northern France, similar to the prevalence in the USA. ${ }^{23}$ Most patients harbour a low worm burden, and heavy infestations are now rarely seen in France. Heavy $T$ trichiura infections are often associated with a colitis termed the trichuris dysentery syndrome (TDS) ${ }^{4}$ It occurs mainly in tropical countries in children who pass bloody stools and may present with rectal prolapse and growth retardation. ${ }^{45}$ Usually, histopathological studies of the caecal mucosa of children with TDS show only minor changes but, in some cases, the mucosa may bleed and be damaged or ulcerated, particularly in the immediate vicinity of the worms. ${ }^{45}$
Apart from a debated relation with some cases of appendicitis, complications requiring surgical intervention are rare in trichuriasis. Two cases of acute ileocolic or caecocolic intussusception have been related to heavy $T$ trichiura infestation. ${ }^{67}$ Trichuriasis has been associated with a granulomatous tumour of the colon $^{89}$ and with intestinal lymphangiectasia. ${ }^{10}$ One case of perforated acute appendicitis in human trichuriasis has been reported, ${ }^{11}$ as well as a case of perforation of the caecum because of obstruction of the ileocaecal valve. ${ }^{12}$ It is difficult to ascertain how the heavy $T$ trichiura infestation led to those complications, and we cannot exclude coincidence. Therefore, such cases have to be reported to question the potential of heavy $T$ trichiura infestation to cause in few patients (maybe with decreased local immunological defences) intense local irritation with pseudotumoral formation, spasm of the intestinal wall or deep ulcerations. The pseudotumour in the present case resulted from a proliferative inflammatory response following intense parasitic infestation.

1 Poirriez J, Dutoit E. Trichocéphales et trichocéphalose. Editions techniques, Encycl Méd Chir (Paris-France), Maladies infectieuses, 8-516-A-25, 1994:4

2 Dutoit E, Ayadi A, Poirriez J, Kamani H, Vernes A, Camus D. Répartition des affections parasitaires digestives et urinaires au C.H.U. de Lille. Bilan de 1972 à 1982. Lille Méd 1987;27:337-40.

3 Kappus KD, Lundgren RG, Juranek DD, Roberts JM, Spencer HC. Intestinal parasitism in the United States: update on a continuing problem. Am f Trop Med Hyg 1994;50:705-13

4 MacDonald TT, Choy MY, Spencer J, Richman PI, Diss T, Hanchard B, et al. Histopathology and immunohistochemistry of the caecum in children with the Trichuris dysentery syndrome. F Clin Pathol 1991;44:194-9.

5 Bundy DAP, Cooper ES. Trichuris and trichuriasis in humans. Adv Parasitol 1989;28:107-73.

6 Huang ACC. Acute ceco-colic intussusception in adult caused by Trichuris trichiura infestation. Report of a case. Chin Med f 1949;67:660-1.

7 Kerrigan KR. Ileo-colic intussusception complicating heavy Trichuris trichiura infection. Tropical Doctor 1991;21:1345 .

Kojima Y, Sakuma H, Izumi R, Nakagawara G, Miyazaki I, Yoshimura $H$. A case of granuloma of the ascending colon due to penetration of Trichuris trichiura. Gastroenterologia faponica 1981;16:193-6.

9 Semenova LS. A case of difficult diagnosis of an intestinal tumour and trichuriasis [Russian]. Medskaya Parazit 1964; 33:491-2

10 Russo EM, Bontempini L. Considerazioni su di un caso raro di linfangectasia intestinale associata a infestazione massiva da Trichuris trichiura con studio bioptico della mucosa intestinale. Pathologica 1981;73:811-15.

11 Arminante JC, De Campos EP. Apendicite aguda perfurativa por infestaçâo de Trichocephalus trichiurus. Revta Inst Adolfo Lutz 1968;28:71-7.

12 Fishman JA, Perrone TL. Colonic obstruction and perforation due to Trichuris trichiura. Am $\mathcal{F}$ Med 1984;77:154-6. 